\title{
Antikythera Mechanism shows evidence of lunar calendar
}

\author{
C. Budiselic ${ }^{1}$, A. T. Thoeni $^{2 *}$, M. Dubno ${ }^{3}$, A. T. Ramsey ${ }^{4}$ \\ New finding from Antikythera Mechanism \\ Based on statistical analysis of micro CT imaging of the more than 2,000-year-old Antikythera \\ Mechanism, we show unexpected evidence establishing a lunar calendar with Egyptian civil-calendar \\ month-names circa 100 B.C. This finding displaces a century-long presumption of a 365-day non-lunar \\ calendar on the Antikythera Mechanism with a 354-day lunar calendar and may inform a fundamental \\ question of the number and type of calendars used in Ancient Egypt.
}

\section{Introduction}

The Mechanism Structure and Features. Since its salvage in 1900-01, the more than 2,000year-old Antikythera Mechanism has proven to be an extraordinary addition to the archaeological record, requiring radical revision of the history of technology. ${ }^{1}$ The extant artifact is an accumulation of 82 fragments of the original device organized into two groups: larger fragments designated A-G, and smaller fragments numbered 1-75. As non-destructive investigative techniques have advanced, this fragmentary evidence has revealed great detail regarding the Mechanism's design and construction, to the degree that the Antikythera Mechanism is accepted as an unprecedented example of the era's considerable astronomical, mathematical, and engineering capacity.

Amongst its many functions can be found the first known physical examples of a pointer referencing finely graduated instrument markings, motion transmission through coaxial shafts, and differential, mathematical, and epicyclic gearing. ${ }^{1,2,3,4,5,6,7}$ The Mechanism purposefully represented celestial concepts such as the ecliptic longitude and phase of the moon, eclipse prediction via the socalled "Saros" cycle, and the lunar anomaly as understood by Hipparchus, with the latter so subtle in its implementation that its contribution would have been barely discernable on the Mechanism's display. It is also widely believed to have incorporated a mechanized display of the five naked-eye planets known in antiquity. 2,3,8,9,10,11 In addition to astronomical indications, the Mechanism displayed calendrical data such as the 19-year Metonic cycle, the four-year cycle of the pan-Hellenic games, ${ }^{12}$ and was apparently designed so as to be able to repeat cycle projections of at least several hundred years. ${ }^{13}$

However, despite a century of scholarly inquiry, some features remain unexplained and notable irregularities invite further investigation. One such feature (and the focus of this paper), is the section of the Mechanism's Fragment C, known as the Front Dial Calendar Ring, which is a divided, movable ring that lies just outside a Zodiac ring, also with divisions (Figure 1).

The extant portion of the Calendar ring of the Mechanism is located in a channel in the front dial plate and was fabricated to rotate freely within the channel. ${ }^{1,7}$ Somewhat less than 25 percent of the original ring remains, and contains graduated marks dividing the ring into what appear to be days. ${ }^{1}$ Underlying the ring (approximately in the middle of the channel) is a matching arc of closely spaced holes, presumed or estimated by many scholars to number, in its original state, $365^{1,6,12,13,14,15,16,17,18,19,20,21}$ (which we argue is incorrect) and believed to have been used to

${ }^{1}$ Cairns, Australia. ${ }^{2}$ University of North Florida, Jacksonville, FL. ${ }^{3}$ New York, NY. ${ }^{4}$ Nikon Metrology, Inc., Brighton, $\mathrm{MI}$.

*Corresponding author: Email: andrew.thoeni@unf.edu 
register the radial position of the Calendar ring. This registration to the holes is understood to have been facilitated by a small peg (or pin) being inserted through the ring into any one of the underlying holes, as required. 1,7,22 Additionally, there are several inscriptions on the Calendar ring itself, including three consecutive Egyptian month names of "Pachon," "Payni," and "Epeiph" inscribed in Ancient Greek. 1,14

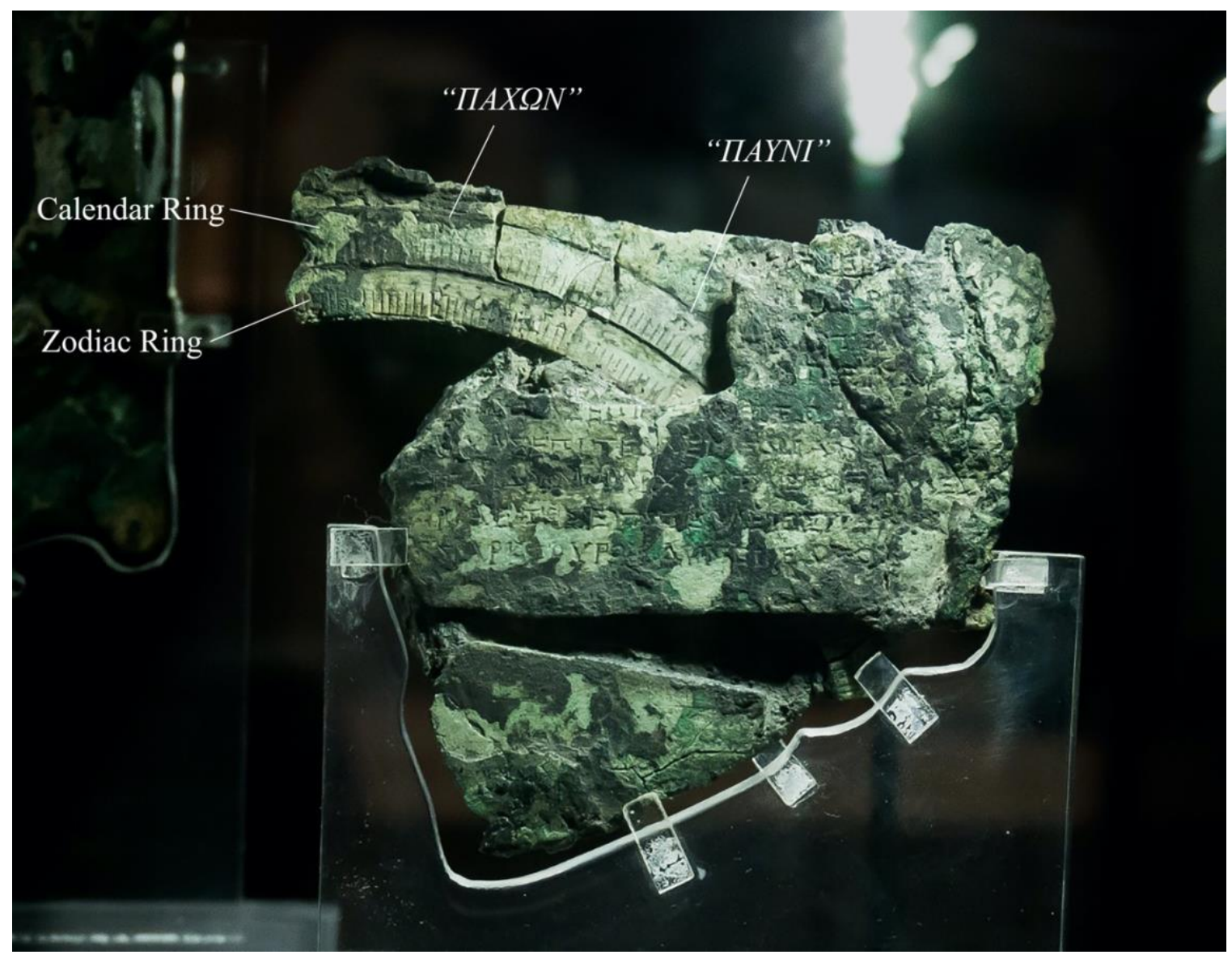

Figure 1. Fragment $\boldsymbol{C}$. The current state of Fragment $C$ allows direct visual inspection of portions of the Calendar and Zodiac rings. The Calendar ring sits in a channel and could have been radially rotated. A portion of the Greek names of the Egyptian months "TAX $2{ }^{2}$ " (Pachon) and "ПAYNI" (Payni) are visible on the Calendar ring, with a letter height averaging 1.8mm. Image use with permission, (C) 2019, David Jones.

A fully extant section of the ring with 30 graduations and the Egyptian month name "Payni" above them, is delineated by lines of slightly longer length, suggesting this specific portion of the ring represents a single month of 30-day duration. ${ }^{1,14}$ The shorter markings could then be reasonably assumed to be day markings of the months. The ring is accepted to have had a calendrical function and although there is no extant evidence of the five epagomenal days associated with the Egyptian civil calendar, it has, nevertheless, been universally presumed to represent the 365-day Egyptian civil calendar. 1,7,12,14,15,22,23,24

Price was the first to formally propose the Calendar ring as an example of the Egyptian civil calendar, although he noted, even without the benefit of modern CT scans, the ring's divisions are visibly spaced somewhat wider than would be expected for 365 divisions. ${ }^{1}$ This was subsequently noted by others ${ }^{24}$ and to reconcile the discrepancy between the physical device and the presumed 365-day calendar, scholars proposed two explanations: construction error ${ }^{1}$ and an intentional non- 
uniform design feature. ${ }^{17,24}$ However, the 365-day count has never been subjected to empirical evaluation, and no alternative hypotheses of a non-365-day calendar have been tested. If a 365-day calendar does not fit the evidence, then where does the evidence lead us?

\section{Methodology and Results}

Methodology Overview. Various efforts have been made to establish critical dimensions of the Antikythera Mechanism's Fragment C. To date, all published attempts to quantify the key dimensions of the Mechanism's Calendar and Zodiac rings have either been based upon comparatively low-resolution single or composite CT images ${ }^{1}$ or was research unconcerned with testing hypotheses of the number of days represented on the Calendar ring and its underlying holes. ${ }^{17,24}$ Focusing our research on the fundamentals of the Calendar ring and testing a hypothesis of 365 holes (days) required a highly accurate approach.

After more than 2,000 years lying underwater, the Mechanism is quite degraded. However, high-resolution $(0.05 \mathrm{~mm}) \mathrm{X}$-ray computed tomography (CT) imaging performed in 2005, provided precise, measurable images of the holes in the channel underlying the calendar ring. ${ }^{25}$ We established our research design to reduce measurement error by 1) taking careful, repeated measures, 2) using only accurately-measurable, extant features, and 3) drawing from the highest resolution X-ray computed tomography (CT) image stacks available. After considering and testing several possibilities (e.g., using calendar ring marks, calendar track edge, fabrication layout markings, circle-fitting, and angular measures), we determined that measurement of the Calendar ring's underlying holes was the most promising. Compared to the engraved markings on the Calendar and Zodiac rings - which are fainter and offer a less-desirable opportunity for interval measurement - many of the holes have been better protected (hidden under the Calendar ring itself) and present a more discrete measurement target. We proceeded taking exploratory measurements of the $\mathrm{x}, \mathrm{y}$ coordinates of the center of all 81 extant holes to validate the image stack and our measurement protocol. Based on our exploratory findings, a new image stack was produced correcting for parallax error. We then reapplied the measurement protocol and gathered a final set of testable data.

Based on the holes' $x$, y center coordinates, and using straightforward mathematics, algebra, and geometry, we were able to calculate the inter-hole distance between each hole pair, chord length between any arbitrary hole pair, radius, arc's angle, the arc's chord length, and the arc's height. Using intersecting chords theorem, ${ }^{26}$ we calculated the circumference and radius of the full hole circle, upon which the 81 holes are distributed. With these data we were able to algebraically determine the $\mathrm{x}$, $\mathrm{y}$ coordinates of the hole circle's center and mathematically determine the expected inter-hole distance for the hypothesized 365 holes around a full circumference. Having calculated the inter-hole values for 365 holes, we tested the hypothesis of the Calendar ring representing a 365-day calendar comparing the expected inter-hole distance for 365 holes to the extant inter-hole distance using the two one-sided t-test (TOST) equivalency procedure.

Image data. Custom images were created by Andrew Ramsey of Nikon Metrology from high-resolution X-ray Computed Tomography (micro CT) images. ${ }^{25}$ An initial $50 \mu \mathrm{m}(0.05$ $\mathrm{mm}$ ) resolution image stack was used for exploratory discovery. Fragment $\mathrm{C}$, while in one physical piece, is not in its solid original state. For example, obvious cracks can be seen between holes 73 and 74 (Figure 2). Smaller cracks appear in numerous places along the ring. 


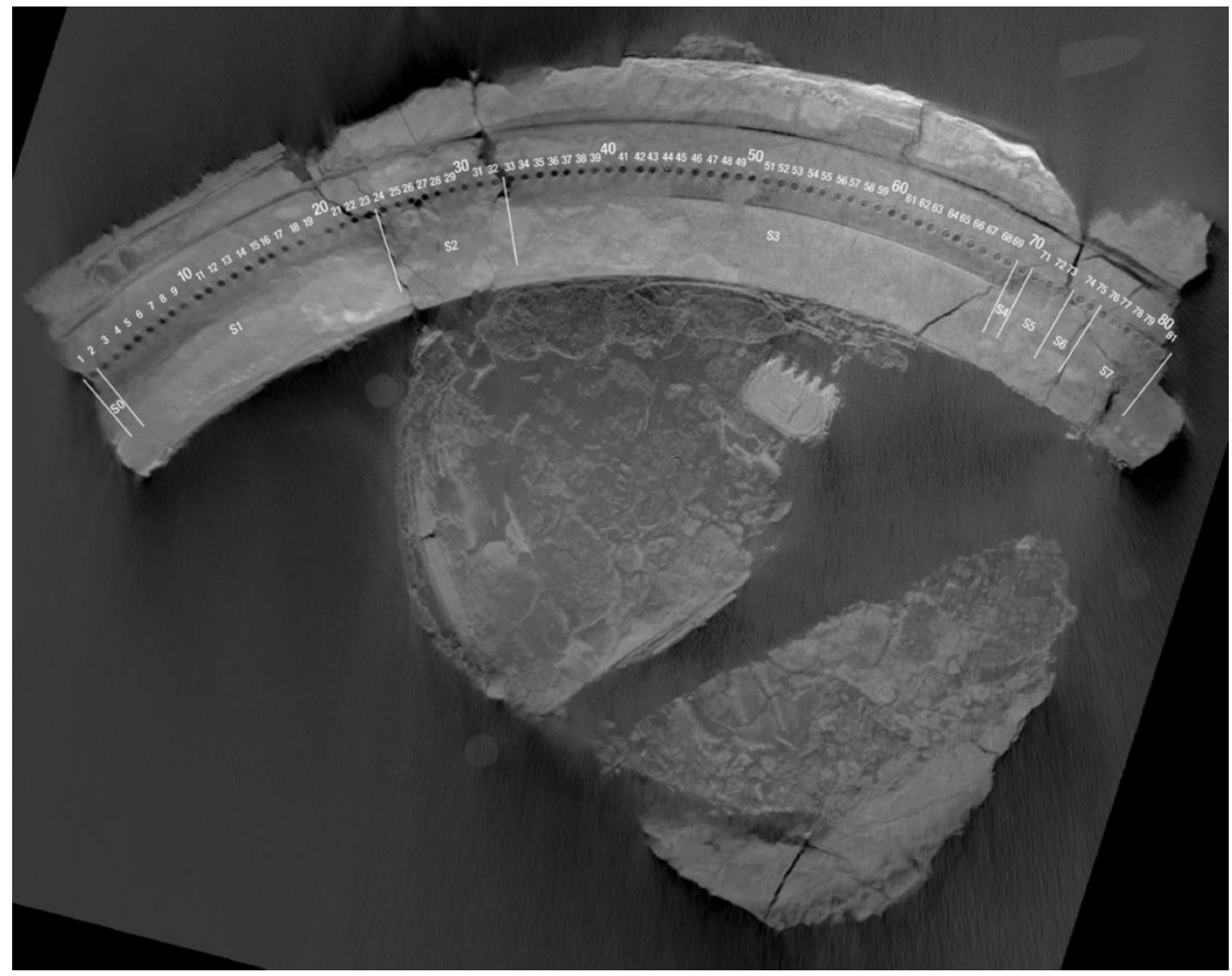

Figure 2. Fragment $\boldsymbol{C}$, composite $\boldsymbol{C T}$ image of holes. Section numbers (marked "S") indicate portions of Fragment $C$ that are bounded by mechanical breaks sufficient to alter radial alignment of holes, thus they are reported in groups. Holes are numbered continuously across sections using the traditional hole numbers.

To identify physical shifting within the fragment, we measured all holes' $\mathrm{x}, \mathrm{y}$, and $\mathrm{z}$ coordinates and performed an ANOVA and pairwise $t$-tests to discover any significant variance between holes pairs and then investigated if high variances were due to a physical defect in the fragment. We discovered seven fractures of varying depths and effects that, if not addressed, could confound measurement. We subsequently defined these as sections S0 to S7. Unsurprisingly, the largest $\mathrm{x}, \mathrm{y}$, and z shifts were on the end sections, S0, S1, and S7, while S2 and S3 in the middle of the extant ring fragment presented much more stable, planar surfaces. Two sections ( $\mathrm{S} 0$ and $\mathrm{S} 4$ ) have only one hole, therefore no inter-hole distances were calculated for these sections.

Since our purpose was to measure hole locations as accurately as possible, a second custom image stack was constructed specifically to minimize parallax error by aligning the largest unfractured section (S3) parallel to the visual plane. The image stack was imported into Fiji ${ }^{27}$ (a distribution of ImageJ scientific image processing software) and pre-processed following applicable procedures from Ushizima et al. ${ }^{28}$ In total, the data-collection stack contained 2,361 images at a $50 \mu \mathrm{m}(0.05 \mathrm{~mm})$ per pixel resolution with $50 \mu \mathrm{m}$ distance between layers.

Data collection and measurement. Our procedure first set the scale in Fiji to match the provided reference of $50 \mu \mathrm{m}$ per pixel (20 pixels per $\mathrm{mm}$ ). Given the conservation state of the 
Mechanism, not all holes were crisply visible. To improve measurement accuracy, we used the center of each hole (eliminating the need to measure hole diameters) and, for a few holes, we used either threshold enhancement, to increase contrast between the hole and surrounding material, or varied the depth of our measurement, finding that using an image layer just below the surface provided a better representation of the hole walls as they were less damaged. Since the holes are essentially perpendicular to the visual plane and the depth difference between frame is only $50 \mu \mathrm{m}$, parallax error is negligible between different image layers.

After establishing a reference point for each hole, our procedure was to enlarge the image to just before the point of pixelation (about $8 \mathrm{x}$ ) and to place a marker at the center of the hole recording an $\mathrm{x}$ and y center location for each of the 81 holes. To reduce measurement error, this procedure was repeated multiple times over different measurement sessions. The procedure continued until we reached measurement saturation, getting consistent results across a minimum of three measurements of each hole. Some holes, though, required as many as eight measurements to reach saturation, defined as a standard deviation of $\leq 0.05 \mathrm{~mm}$, but we reached a maximum std. dev. of less than 0.037 $\mathrm{mm}$. A total of 274 measurements were collected and exported from Fiji into a data set suitable for analysis. These data were then summarized (mean $\mathrm{x}$, mean y), by hole, reducing the collected data to 81 observations. The summarized data are available as noted in the Acknowledgements below.

Calculations. We used the mean $\mathrm{x}$ and y locations for the 81 holes as the base data upon which to make all our calculations. After accurately locating the hole-center positions, our general procedures were 1) calculate the inter-hole distances, chord length, and radius, 2) calculate the circumference based on the radius, and 3) determine the expected inter-hole distance for 365-hole rings based on the circumference.

Inter-hole distance. An inter-hole distance was calculated for each hole-pair. For example, starting at hole one the distance to hole two was calculated using $\sqrt{\left(\left(x_{1}-x_{2}\right)^{2}+\left(y_{1}-y_{2}\right)^{2}\right)}$. Since existing fractures could give false readings, we calculated inter-hole distances between each subsequent pair (hole two to three, three to four, and so on) until we reached the end of a section, delineated by a fracture in the plate. From there, we started the procedure again using the first hole in the next section as the initial hole. Thus, we calculated a total of 74 inter-hole distance measurements.

When calculating the chord length, radius, arc angle, and arc height, we were aware the fractures caused each end of the ring, along with the respective holes, to diverge from its original concentricity. To avoid errors that would result from these misalignments, we used the largest unbroken section of the fragment - section S3, which contains 37 holes or about 10 percent of the ring's full circumference - and calculated the chord length, radius and arc height of the section based only on the holes' measured $\mathrm{x}$ and $\mathrm{y}$ coordinates.

For clarity, the intersecting chords theorem ${ }^{26}$ states a circle's radius can be calculated with only three points along an arc of a circle. To be sure, the larger the arc, the less measurement error affects the results. However, since we were able to measure the holes with sufficient accuracy to reach statistical significance (see Hypothesis testing below), the extant arc is sufficiently accurate to determine the radius of the original circle within a very close approximation.

Chord. We calculated the chord length using the same formula as the inter-hole distances but used the first and last holes on section S3 (holes 33 and 69) as the endpoints. Therefore, $\sqrt{\left(\left(x_{33}-x_{69}\right)^{2}+\left(y_{33}-y_{69}\right)^{2}\right)}$.

Radius. To determine any length, radius included, one must have a starting and ending point. Each hole around the circumference is an ending point radiating from the center of the circle. We initially algebraically solved for the x-center and y-center using the middle hole and two end 
holes of S3 (50, 33, and 69, respectively) producing three equations, $\left(x_{33}-x_{c}\right)^{2}+\left(y_{33}-y_{c}\right)^{2}$, one for each hole, allowing us to solve for two variables, the center's $\mathrm{x}$ and y coordinates. However, each hole shows slight, random variation from the maker's hand, so slightly different radii (and therefore circumferences) would result depending on which three holes were selected to perform the radius calculation. To reduce this error, and to eliminate selection bias, we generated every possible combination of three-hole sets, removed combinations with duplicate holes and, to maximize accuracy, kept only chords of at least half the width of the arc. We used these to determine the radius. In all, radii were calculated using the procedure above for 26,220 threehole combinations and the mean radius of these was used in further calculations.

Arc angle, height, and length. The angle subtended by the arc was calculated using: degrees $(2 * \arcsin ($ chord $/(2 *$ radius $)))$. The arc's height was calculated using: radius $\times(1-$ $\cos ($ radians $(\operatorname{arc}$ angle $) / 2)$ ). The arc's length was calculated using: radians (arc angle $) \times$ radius

Circumference. Finally, the circumference of the full circle was calculated as $2 * \pi *$ radius. Results of all calculations are shown in Table 1. Note that while the image's resolution limits direct measurement to only two decimals, we present all data to three decimals to reduce information loss when rounding mean measures of hole locations. In our actual calculations, precision was only limited by the computer's capability (64-bits).

Expected inter-hole values. After the circumference was defined, we could determine the mean inter-hole distance that would be present if the maker had intended any given number of holes. For example, with a circumference of $486.77 \mathrm{~mm}$, if the maker intended 100 holes, we'd expect to see about $4.868 \mathrm{~mm}$ between each hole. However, we are most interested in testing the null hypothesis related to the maker's intention of representing an Egyptian civil calendar (365 holes). Therefore, we calculated the expected inter-hole distance using: circumference / no. of holes, which for 365 holes is $1.334 \mathrm{~mm}$. We include other inter-hole distances (360 and 354), which are discussed later in the text.

\begin{tabular}{|l|c|}
\hline Measure $(\mathrm{n}=74)$ & Value \\
\hline Inter-hole distance & $1.365 \mathrm{~mm}$ \\
\hline Inter-hole std. dev. & $0.127 \mathrm{~mm}$ \\
\hline Inter-hole std. error of mean & $0.015 \mathrm{~mm}$ \\
\hline Inter-hole upper CI $(99 \%)$ & $1.404 \mathrm{~mm}$ \\
\hline Inter-hole lower CI $(99 \%)$ & $1.326 \mathrm{~mm}$ \\
\hline Radius (n=26,220) & $77.493 \mathrm{~mm}$ \\
\hline Radius upper CI $(99 \%)$ & $77.548 \mathrm{~mm}$ \\
\hline Radius lower CI $(99 \%)$ & $77.438 \mathrm{~mm}$ \\
\hline Chord length & $48.058 \mathrm{~mm}$ \\
\hline Arc angle & $36.128^{\circ}$ \\
\hline Arc height & $3.820 \mathrm{~mm}$ \\
\hline Arc length & $48.864 \mathrm{~mm}$ \\
\hline Circumference & $486.901 \mathrm{~mm}$ \\
\hline 365 expected inter-hole distance & $1.334 \mathrm{~mm}$ \\
\hline 360 expected inter-hole distance & $1.353 \mathrm{~mm}$ \\
\hline 354 expected inter-hole distance & $1.375 \mathrm{~mm}$ \\
\hline $\begin{array}{l}\text { Table 1. Summary of Calendar hole measurements and calculations. } \\
\text { Summarized here are results of measures and calculations (as described in the text). Key } \\
\text { measures are inter-bole distance, radius, and the expected inter-bole distances. }\end{array}$ \\
\hline
\end{tabular}


Hypothesis testing. We next turned our attention to the main null hypothesis: that the number of holes underlying the Calendar ring is 365 (of the Egyptian civil calendar). Our research design made this a simple matter of mathematics. As established above, the extant mean inter-hole distance is $1.37 \mathrm{~mm}$. If there were originally 365 holes, then the extant mean inter-hole distance would be the circumference divided by 365 , giving $1.33 \mathrm{~mm}(486.90 \mathrm{~mm} \div 365)$. Inter-hole distances greater than $1.33 \mathrm{~mm}$ suggest fewer holes, as they must be placed farther apart along a given circumference. If, by contrast, there were originally 354 holes, the expected mean interhole distance should be $1.375 \mathrm{~mm}(486.90 \mathrm{~mm} \div 354)$. Here it is important to note that inter-hole distances discussed appear small, but the sum of these differences around the full circumference is about $15 \mathrm{~mm}$ and the very essence of statistical testing is to determine if there is sufficient evidence, given the number of observations present, to be trusted at a set confidence threshold. In our tests, we use $99 \%$ confidence levels $(a=0.01)$ for assessment and found a statistically significant outcome.

One of the most often used statistical tests is Student's $t$-test. Typically used to compare means between two groups, it can also compare a group's mean to an expected value (e.g., extant inter-hole mean to the expected inter-hole distance of a hypothesized number of holes). ${ }^{29}$ However, Student's $t$ is designed to test for difference, not equivalence, and can also cause one to fail to reject the null hypothesis merely because a small sample size does not produce significance, and even though an effect may be present. Likewise, a high sample size will often produce significance though the practical effect may be trivial. ${ }^{30}$ Researchers interested in testing for equivalence base their assessment on effect size using the TOST procedure to validate equivalency.

To execute the test, one specifies a confidence level (a), a value to be considered practically zero (we reference as $z$ ), and the expected mean value $(\mu)$. The test results are then given as either one can, or cannot, conclude the expected value is practically equivalent to the extant value. In this instance, it is important to note these tests do not rely on single direct inter-hole measures or even the single inter-hole mean (which are both relatively small), but instead on the calculated circumference based on chord measurements between two holes as long as $48 \mathrm{~mm}$, reducing the potential for error based on the small inter-hole distances. Also, the tests are considering the mean of all 74-hole pairs, not just a single hole pair.

We performed the TOST procedure following established methodologies ${ }^{30,31}$ using JMP Pro $^{32}$ statistical software selecting values of $\mathrm{a}=0.01, \mathrm{z}=0.05$, and an expected inter-hole distance for 365 holes of $\mu_{365}=1.334 \mathrm{~mm}$ (circumference of $486.901 / 365$ expected holes), and compared to the extant inter-hole distance of $1.365 \mathrm{~mm}$. We selected 0.05 as z since it was the established limit of the images' resolution, therefore practically zero.

For the 365-hole test, we found a maximum $p$ value of 0.1020 and an effect size, Cohen's $d$, of 0.224, which do not support equivalency. That is, there is no evidential support that the ring comprised 365 holes, as $p$ must be less than 0.01 . Therefore, we reject the null hypothesis of the ring containing 365 holes.

Determining the Likely Hole Count. After rejecting the null of 365 holes, we turned our attention to establishing the likely hole count. Using the same TOST procedure, we tested 24 possible hole counts ranging from 347 to 370, and included within this range are 360 and 354, two values with potential calendrical significance. Figure 3 charts the TOST's maximum pvalues for each hole count. Here we see all points that fall within the range of significance (red 
points below dotted line). Some division counts (blue points on left) place the holes too far apart to match the extant inter-hole distance, while others (blue points on right) pack the holes too closely to match the extant inter-hole distance. We found that hole counts from 354 to 359 were significant at 99 percent, and that hole count 360 fell just outside significance at 98.7 percent.

For the 354-hole test, we found a maximum $p$ value of 0.0046 and $d$ of -0.082 , providing supporting evidence that the extant inter-hole distance of the Calendar ring's holes is equivalent to the inter-hole distance of 354 holes. This shows 354 holes is statistically slightly more likely than 360 holes but substantially more likely than 365 holes, which has a p-value 10 times higher than the threshold.

The TOST procedure measures the concept of equivalency based on effect size. For example, if a drug manufacturer wants to show their generic version is equivalent to the brand version, then the difference in effect should be practically zero. Cohen's $d$ shows the size of the effect and, unlike the $p$ value, is independent of sample size. ${ }^{30}$ Cohen's rule-of-thumb for effect size is $\geq 0.2$ is a small effect, $\geq 0.5$ is a medium effect, and $\geq 0.8$ is a large effect. ${ }^{33}$ Cohen described a small effect as one that is real, but that requires careful observation to detect. ${ }^{33}$ Absolute values of $d$ well below 0.2 are considered trivial, that is, the difference in two observations that have a low value for $d$ are not practically meaningful, and as such those two observations are practically equivalent, based on the TOST definition of practically zero (z).

Therefore, the 365 -inter-hole mean's $d$ value of 0.224 is interpreted as being different than the extant inter-hole mean. Likewise, the 354-inter-hole mean's absolute $d$ value of 0.082 is interpreted as being the same (no practical difference) as the extant inter-hole mean. For clarity, since a difference of zero cannot be calculated in the TOST procedure, one must specify the difference greater than zero that is considered practically zero. As noted above, for our testing, we used $0.05 \mathrm{~mm}$ as being practically zero. Table 2 gives a summary of the TOST results.

\begin{tabular}{|l|r|r|r|r|r|r|r|}
\hline Test $(\alpha=0.01)$ & $\boldsymbol{t}$ & $\max \boldsymbol{p}$ & DF & Lower Cl & Upper Cl & SE & Cohen's $\boldsymbol{d}$ \\
\hline TOST $\mu_{365}=1.334 \mathrm{~mm}$ & -1.2817 & 0.1020 & 73 & 1.3259 & 1.4041 & 0.014 & 0.224 \\
\hline TOST $\mu_{360}=1.353 \mathrm{~mm}$ & -2.5348 & $0.0067 * *$ & 73 & 1.3259 & 1.4041 & 0.014 & 0.098 \\
\hline TOST $\mu_{354}=1.375 \mathrm{~mm}$ & 2.6782 & $0.0046^{* *}$ & 73 & 1.3259 & 1.4041 & 0.014 & -0.082 \\
\hline
\end{tabular}

Table 2. TOST Procedure Results. These tests of equivalency for 365, 360, and 354 boles show 365 holes as being not equivalent, based on Cohen's d, to the extant measures but 360 and 354 boles being practically the same (per Cohen), with 354 boles being slightly more equivalent than $360 .{ }^{* *}$ Significant at 0.01 .

Other Literature. Though no authors have proposed 354 as the number of holes, many have reported the underlying data that would suggest 365 holes is very unlikely. Table 3 holds a brief analysis of all papers reporting either a direct measure of the hole circle's radius (marked $\dagger$ ) or measures from which one can directly calculate the radius (marked*). For papers where we calculated the hole circle's radius, we used the middle of the Calendar ring, which is a conservative measure since the hole circle lies closer to the center than the middle of the Calendar ring's width.

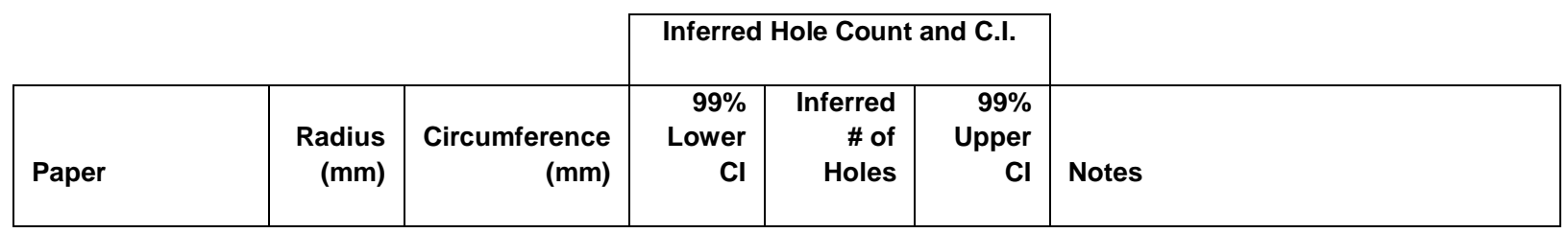




\begin{tabular}{|c|c|c|c|c|c|c|}
\hline $\begin{array}{l}\text { Budiselic et al. } \\
\text { (this paper) }^{\dagger}\end{array}$ & 77.49 & 486.90 & 346.8 & 356.7 & 367.2 & $\begin{array}{l}\text { Based on equal-probability Monte Carlo } \\
\text { analysis of all hole-set combinations } \\
(\approx 26,000) \text { for Section } C \text { holes. }\end{array}$ \\
\hline $\begin{array}{l}\text { Evans \& Carman, } \\
2019^{\dagger}\end{array}$ & 77.10 & 484.43 & 345.0 & 354.9 & 365.4 & $\begin{array}{l}\text { Hole circle radius directly reported } \\
\text { based on sum of squared residuals of } \\
\text { as yet unreported number of } \\
\text { measurements of holes. Pg. } 632 \text { notes } \\
\text { accuracy may not be "terribly precise" } \\
\text { based on unknown validity of the } \\
\text { original photograph's } 5 \mathrm{~cm} \text { scale } \\
\text { provided to the authors. }\end{array}$ \\
\hline $\begin{array}{l}\text { Evans et al., } \\
2010^{*}\end{array}$ & 72.59 & 456.11 & 324.8 & 334.1 & 344.0 & $\begin{array}{l}\text { Calculated center of hole circle using } \\
\text { least-squares fit of measured } x \text { - and } y \text { - } \\
\text { coordinates of holes } 1-73 \text {. The authors } \\
\text { report the radius of the outer edge of } \\
\text { the Zodiac ring. We add half the mean } \\
\text { of Wright's and de Solla Price's } \\
\text { Calendar ring width ( } 3.675 \mathrm{~mm}) \text { to } \\
\text { arrive at a conservative measure of the } \\
\text { hole circle's radius. }\end{array}$ \\
\hline Wright, 2006* & 75.15 & 472.18 & 336.3 & 345.9 & 356.1 & $\begin{array}{l}\text { Wright reports, pg. } 324 \text {, the radii of } \\
\text { various features. We used the middle of } \\
\text { the Calendar ring's reported width as a } \\
\text { conservative measure for the hole } \\
\text { circle's radius. }\end{array}$ \\
\hline $\begin{array}{l}\text { de Solla Price, } \\
1974^{*}\end{array}$ & 73.60 & 462.44 & 329.3 & 338.8 & 348.8 & $\begin{array}{l}\text { On pg. 17, de Solla Price gives the radii } \\
\text { of the inner and outer edges of the } \\
\text { Calendar ring. We use the mean of } \\
\text { those as a conservative measure of the } \\
\text { hole circle's radius. }\end{array}$ \\
\hline
\end{tabular}

Table 3. Summary of all previous authors' hole circle radii and inferred mean hole count. The inferred mean for all previously published papers is much lower than 365, in fact lower than 360. While no papers performed hypothesis testing on the number of holes, all papers show stronger evidence than this paper's conservative assessment. Papers marked † reported direct measure of the hole circle's radius; those with * report measures allowing direct calculation of radius.

For each paper we divide the circumference by the extant inter-hole distance (and its 99 percent C.I. measures) to arrive at the number of inferred holes. In summary, no author has presented a radius for the hole circle greater than the one presented in this paper, meaning all other papers provide even stronger evidence that 365 holes is outside (or very nearly outside) the full 99 percent confidence interval based on extant inter-hole distances and as shown for this paper in Figure 3. 


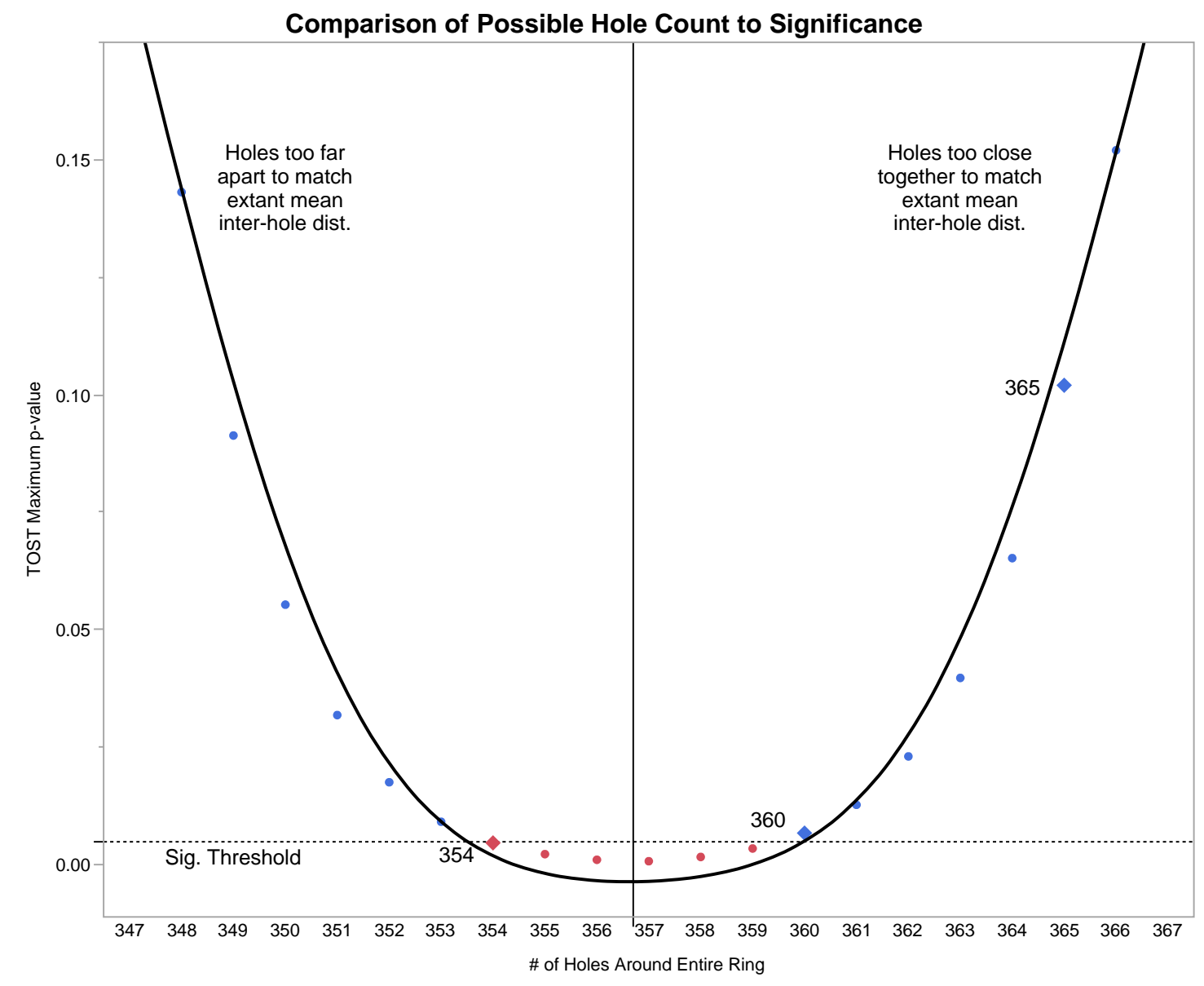

Figure 3. P-value by inferred hole count. Tests of equivalency (TOST) results are shown as p-values along the $y$-axis, by inferred bole count (x-axis). Widely accepted calendar systems $(354,360$, and 365) are marked with a diamond, other bole counts with a dot. All red marks are below the alpha of 0.01 (99\%) and are, therefore, significant.

We also reviewed explanations in literature that propose to account for the observed inter-hole variation, namely construction error ${ }^{1}$ and intentional non-uniform division. ${ }^{17,24}$

To reconcile a proposal for 365 holes vs. 354 holes, a total progressive error of $15 \mathrm{~mm}$ $((365-354) * 1.37 \mathrm{~mm})$ would need to occur around the circumference of the ring. Figure 4 shows the residual error of each hole-pair's inter-hole distance from the mean. Instead of seeing a pattern of purposeful, progressive variation, we see varied error about the mean, indicating construction error is unlikely to account for $15 \mathrm{~mm}$ of total circumference progressive variation required to make the ring 365 holes. Moreover, with a standard deviation of only $0.13 \mathrm{~mm}$, the maker was surprisingly precise given the tools presumed to be available. 


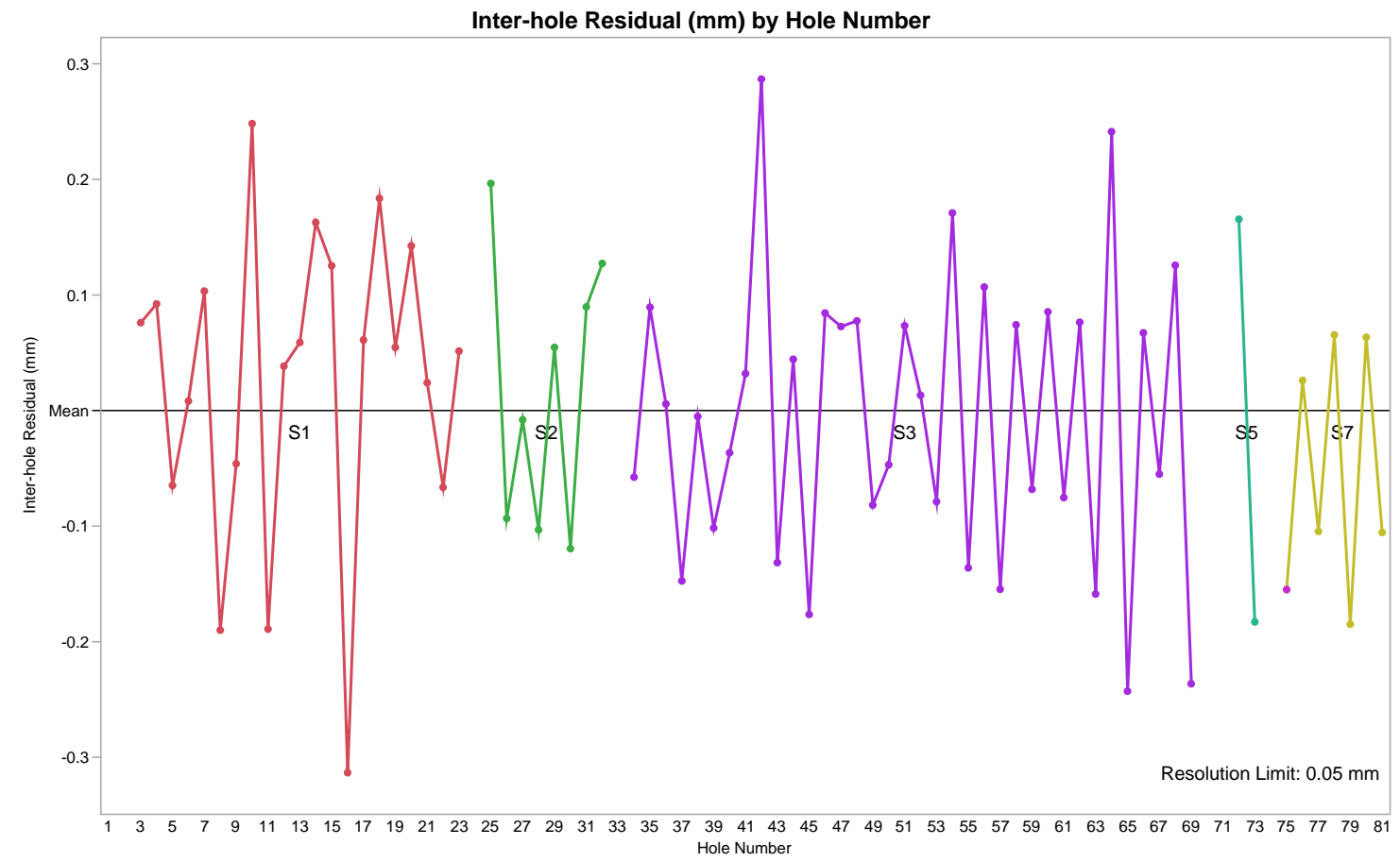

Figure 4. Inter-hole residuals by hole number. Instead of exbibiting planned and progressive variation one would expect with intentional non-uniform division, the residuals indicate error about the mean one could attribute to workman error, but insufficient in sum to account for a proportional component of the required $15 \mathrm{~mm}$ of total circumference variation. Sections are colored and notated. Sections 4 and 6 have insufficient holes to calculate residual variation.

We therefore find the divisions of the calendar ring were intended to be, and for practical purposes are, uniform. We find this to be supported even in papers that propose an alternative explanations for the Calendar ring discrepancy. For example, Evans et al.'s 2010 argument presumes a uniformly divided 365-day Calendar ring, as an attempt to reconcile the Zodiac and Calendar ring graduated markings. ${ }^{24}$ To do so, they propose intentional, non-uniform division of the Zodiac ring as part of an off-axis representation of the solar anomaly. Had the authors explored the possibility of uniform division of both rings, the reconciliation would have been immediately clear with the extant 354-day Calendar ring.

Specifically, the authors calculate a span of degrees of the Zodiac ring as it relates to a span of adjacent days on the Calendar ring. They calculate, for example, $\left(238^{\circ}-169^{\circ}\right) *$

(365.25 days $/ 360^{\circ}$ ), which is 70.01 days, and report it does not match by more than two days their reading of 67.89 days presented on the Mechanism. However, if we substitute 354 days into their calculation, we see that $\left(238^{\circ}-169^{\circ}\right) *\left(354\right.$ days $\left./ 360^{\circ}\right)$ results in 67.85 days, less than one hour's difference from their measurement of the Mechanism.

The authors also state that $29^{\circ}$ on the Zodiac ring equals 28.5 days on the Calendar ring. This results in $28.5 *(360 / 29)$ or 353.79 days - not close to 365 days but nearly exactly 354 days. In each instance, Evans et al.'s data support the finding of uniform division of both the Calendar and Zodiac rings, at 354 days and 360 degree intervals, respectively.

In a subsequent article ${ }^{17}$ the authors explicitly confirm uniform division of the Calendar ring holes and engraved markings, and provide other data informative from the perspective of our finding. A scale factor, and a calculated Photoshop dimension (provided in a footnote) permits the determination that their calculated hole circle radius based on hole measurements alone 
$(77.10 \mathrm{~mm})$ is very close to, but tellingly, smaller than our radius of $77.49 \mathrm{~mm}$. Using this 77.10 $\mathrm{mm}$ radius and the extant inter-hole distance of $1.365 \mathrm{~mm}$, one finds 354.9 holes $(77.10 \mathrm{~mm} * 2 \pi$ / $1.365 \mathrm{~mm}$ ), again, very nearly 354 holes.

A Brief Investigation of Calendar and Zodiac Graduated Markings. Although we have found support for 354 holes, there is no extant feature on the Mechanism that confirms the Calendar ring used the holes for registration, or that the graduated lines on the Calendar ring were necessarily intended to align 1:1 with the underlying holes. To carry the analysis to completion, we devised a straight-forward method to test the marks on the Calendar and Zodiac rings that relies as little as possible on the measurement of the marks since, as noted above, many are quite faint from exposure, hampering precise measurement.

For each section of the Calendar ring, and the full graduated section of the Zodiac ring, we selected a verifiable starting and ending mark and, using the now established center point, were able to measure an angle between the two marks. We then simply counted the number of marks between these points and calculated the inferred number of divisions using: $360^{\circ} \%$ (measured angle/no. of marks). Results are shown in Table 4.

\begin{tabular}{|l|r|r|r|}
\hline Area Measured & $\begin{array}{r}\text { Extant } \\
\text { Divisions }\end{array}$ & $\begin{array}{r}\text { Measured } \\
\text { Angle }\end{array}$ & $\begin{array}{r}\text { Inferred } \\
\text { Divisions }\end{array}$ \\
\hline Zodiac Ring & 76 & 75.81 & 360.90 \\
\hline Calendar Ring (Full Arc) & 68 & 69.19 & 353.81 \\
\hline Calendar Ring (Series 1) & 16 & 16.32 & 352.94 \\
\hline Calendar Ring (Series 2) & 11 & 11.23 & 352.63 \\
\hline Calendar Ring (Series 3) & 36 & 36.34 & 356.63 \\
\hline Calendar Ring (Grand Mean of 1, 2, and 3) & & & 354.07 \\
\hline Calendar Ring (Weighted Mean of 1, 2, and 3) & & & 354.99 \\
\hline
\end{tabular}

Table 4. Results of various division tests of Zodiac and Calendar rings. Results show approximately 360 marks on the Zodiac ring and approximately 354 marks on the calendar ring.

So whilst it is not central to our discussion, nor do our results depend on the measure, results show the Zodiac ring has an inferred 360.90 divisions (closely matching the expected 360) and the Calendar ring gives a range of 353.81 divisions (the full arc) to 354.99 (mean of three sections), putting 354 within this range - and 360 and 365 divisions well outside.

\section{Conclusion}

The physical evidence does not support the Mechanism having a 365-division Calendar ring. Therefore, we must set aside the notion that the Front Dial Calendar Ring of the Antikythera mechanism is a representation of the so-called 365-day Egyptian civil calendar. Nevertheless, given that the feature clearly is a calendar, an alternative proposal is needed, and we find 354 and 360 as the two most likely division candidates based on the precedent of known calendrical systems. Both division candidates may be considered lunar in character; 354 days explicitly so, and 360 implicitly, assuming the concept of twelve nominally "full" 30-day lunations. Based on the significant finding for 354 holes matching the extant inter-hole distance, the confirmation of others' measurements, and our own measurements of the Calendar and Zodiac rings' markings, we interpret 354 divisions as the most likely of these two division candidates and propose that the Front Dial Calendar Ring of the Antikythera Mechanism is a 354 day lunar calendar.

Whilst this finding is somewhat unexpected, we propose that interpretation of the Front Dial Calendar ring as a lunar calendar neatly reconciles this new information with the known attributes of 
the Mechanism. Before proceeding, it is worthwhile defining what we mean by a 'lunar calendar'. For the purposes of keeping our discussion straight forward, and within the context of what we believe to have been the intended role of the calendar ring, we define our conjectured lunar calendar (hereafter simply referred to as the 'lunar calendar') as a circular ring displaying a uniform pattern of 354 engraved markings, delineated by slightly longer engraved markings into an as-yet-unknown combination of six series of 29 intervals, plus six series of 30 intervals, so as to represent exactly 12 successive lunations (a lunation being one lunar cycle). If we take the engraved intervals to represent solar days, then this definition suggests a calendar with an obviously imperfect 29.5 day approximation of the mean lunation (and thus, an imperfect approximation of a solar day), and yet a precise representation of 12 lunations over the span of the ring. Both of these attributes are important, because as we shall see later, we propose that both the exactly defined lunisolar period relationship of the Metonic and Callipic cycles, as well as the 'close enough' approximation of a solar day interval, could have been used in the operation of this part of the Mechanism.

Implied undiscovered gearing. Our finding requires no modification to the accepted understanding of the Mechanism's extant gearing, or the functions of its Metonic, Saros, and subsidiary dials.

However, if we now consider the 354-hole ring in the role of a lunar calendar-and accept that it was intended to indicate successive lunations - then we must also expect some sort of 'day pointer' to communicate this information. To be consistent with the design of what survives of the Mechanism's gearing, such a day pointer must also reasonably conform to the period relation of the Metonic cycle.

We therefore propose that a small gear-train platform (see Figure 5) was planted on the extant 'lug' ${ }^{6}$ on the main solar drive wheel, B1, carrying epicyclic gearing with tooth counts and ratios of 20/95, 14/96, and 52/52. The arithmetic that illustrates its basis in the Metonic cycle is as follows:

\section{A: 20 (fixed sun)}

B: 95 / C: 14

D: 96 / (E: 52)

(F: 52)

Note the tooth counts of $\mathrm{E}$ and $\mathrm{F}$ have no special meaning, they are simply chosen to have the same tooth count as each other (with a reasonable module), to idle transfer and reverse the motion of D back to the pointer shaft.

The expression to calculate the ratio $\mathrm{R}$ is:

$$
\begin{aligned}
& \mathrm{R}=\mathrm{BD} /((\mathrm{BD})+(\mathrm{AC})) \\
& =95 * 96 /\left(\left(95^{*} 96\right)+(20 * 14)\right) \\
& =9120 / 9400 \\
& =19 * 12 * 40 / 235 * 40 \\
& =(19 / 235) \times 12
\end{aligned}
$$

(i.e., exactly 12 lunations as defined by the Metonic cycle, for one turn of the day pointer) 


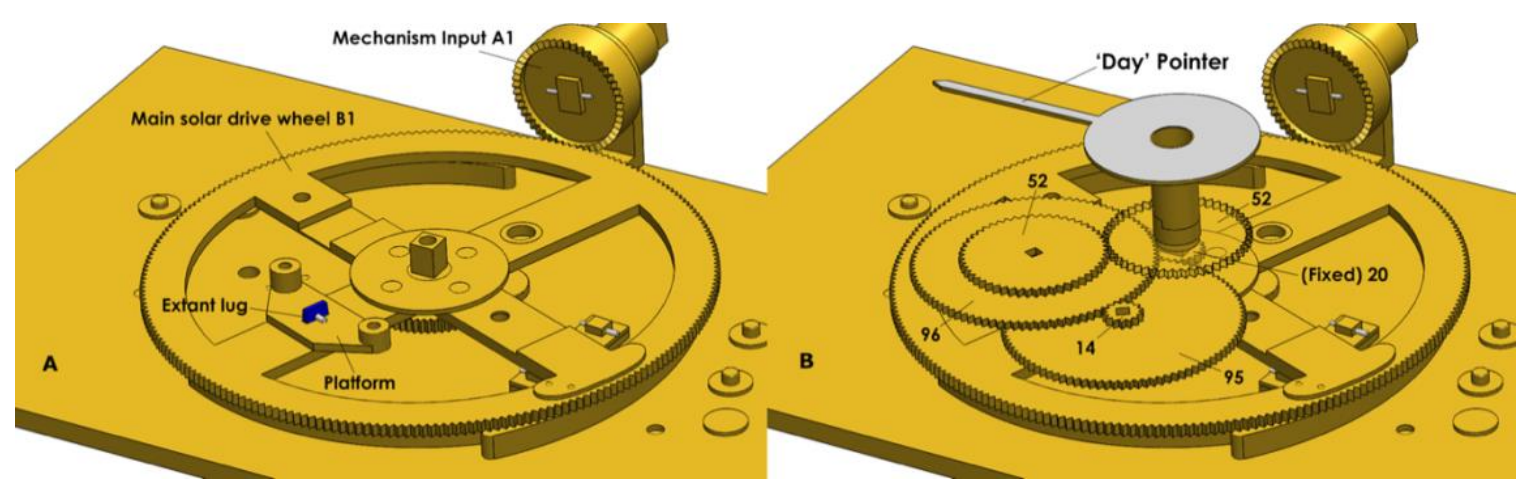

Figure 5. Conjectured Antikythera Mechanism 'day pointer' gearing design. Left image ("A') shows the extant lug location we propose was possibly used to mount a gear train to drive a pointer that communicated the passage of lunations as defined by the Metonic Cycle. Right image ("B") shows that proposed epicyclic gear train, and its associated day pointer.

A pointer driven by this gear train, traversing the lunar calendar ring, would have been exactly synchronized with the pointers traversing the Metonic and Saros dials on the back of the Mechanism. In fact, it is conceivable that interpretation of the somewhat coarser lunation presentation of the Metonic dial would have been assisted by the finer grained detail of the lunar calendar, much as a minute hand relates to an hour hand in a modern clock face display. Whilst the day intervals are approximations of a true solar day length, the day information presented on the lunar calendar would have been perfectly suitable to determine, for example the number of days until a given event, such as a full or new moon.

A solution to the day pointer conundrum. Several scholars have proposed planetarium structures that include a true solar longitude pointer. ${ }^{6,7}$ It has also been noted by others that such a pointer could be considered unsuitable as a 'day pointer' traversing a 365-day Calendar ring, since representation of the true position of the sun would lead to up to a two-day error in the 'solar day' indication. ${ }^{22}$ Until now this has been presented by some scholars as something of a conundrum, since both a day pointer and true solar longitude pointer are reasonable suppositions, and yet on a 365-day Calendar ring they would somewhat illogically appear to indicate much the same information. ${ }^{17}$ Our proposed gearing neatly resolves the conundrum, given that a day pointer on a lunar calendar articulates distinctly different information from a pointer representing true solar longitude.

However, it should be noted that while the 6,940-day Metonic cycle upon which this lunar day pointer gearing is based provides a reasonably practical reconciliation between the lunar and solar cycles over a 19-year period, it was understood in antiquity to have been an approximation with a small error. ${ }^{34}$ Using a solar year period of 365.25 mean solar days, Callippus identified an excess of approximately six hours (a bit over $1 / 4$ of a day) of error in the 19 -year cycle, which amounts to a single day error in 76 years (i.e., four Metonic cycles). ${ }^{34}$ In essence, gearing based upon the Metonic cycle would have been known to be travelling slightly slow. The Callippic cycle purports to addresses this small 'slow' error by skipping a single day every 76 years, as a corrective measure, and so is defined as 27,759 days $((4 * 6,940)-1=27,759)$ over the course of 76 (tropical) years and 940 lunations.

A periodic correction to the Metonic based gearing. The Mechanism displays evidence suggesting the existence of a Callippic dial, whose purpose would likely have been that of a prescriptive indicator to invoke a one-in-76-year correction event that regulated the Mechanism's 
Metonic calendar. ${ }^{22,23}$ A lunar pointer articulating successive lunations as defined by the Metonic cycle would also exhibit the same 'slow' error, and would logically have required inclusion in the same Callippic cycle correction event.

It has been suggested that the skipped day might have been the last day of the fourth Metonic cycle, i.e., the last day of the 76 -year Callippic cycle, ${ }^{23}$ and it can be appreciated that such a correction is not particularly straight forward to execute in a mechanism with complex, inter-related calculation trains. It should also be noted that the correction is not simply achieved by winding the Mechanism forward by one day into the first day of the next cycle, because with such an action the gearing ratio does not change and so no correction would occur. The Mechanism's lunar day and Metonic pointers would simply continue their angular motion according to the uncorrected gearing of the Metonic cycle, ignoring the intent of the Callippic cycle altogether. In order to remain faithful to the purpose of the Callippic cycle, a genuine subtraction of a day from the four consecutive Metonic cycles is required, so from the operator's perspective, the inherent error of the Metonic cycle is corrected, without angular advancement of the Metonic calendar pointer.

We propose the maker may have solved this issue by implementing a very practical solution: When the skipped-day event was indicated by the Mechanism's Callippic dial, the operator would adjust the Calendar Ring position and lunar phase assembly.

To do so, firstly, the front dial Calendar Ring would be unpinned, rotated, and re-pinned, onehole position counter-clockwise (i.e., one day), skipping a day on the lunar Calendar ring. This day interval, whilst not strictly correct in duration, is an acceptable approximation of a true day interval for this small corrective move, and would effectively correct the Mechanism gearing according to the Callippic cycle's inferred mean lunar and solar periods, as measured in days. Importantly, whilst the Metonic calendar pointer tip would have required the usual reset to the inside of the spiral brought about by the completion of a Metonic cycle, there would have been no angular advancement of the Metonic calendar pointer.

Secondly, the lunar phase assembly would be adjusted by advancing it forward by the equivalent of a single day's lunar longitude and phase, most effectively using a friction fit connection to the shaft driving this assembly. One such way this may have been implemented is via a peened (or slightly bent) retaining pin, as shown in Figure 6. With such an arrangement, the operator would simply use finger pressure to overcome the friction between the retaining pin and the drive shaft to advance the lunar phase assembly, much like one might set the time on a modern clock.
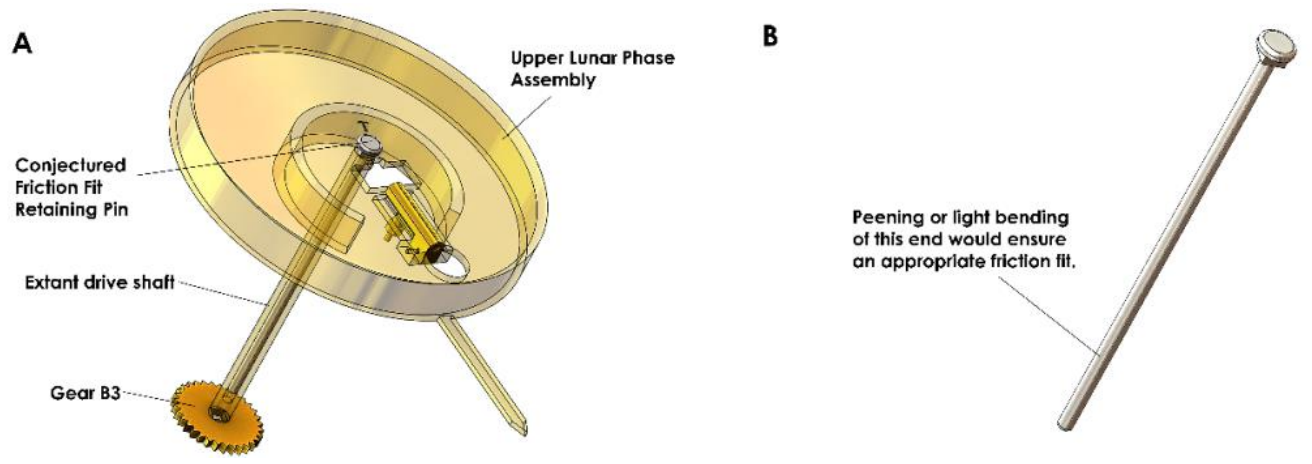

Figure 6. Conjectured Lunar Phase Assembly Friction Fit Retaining Pin. Left image ("A") shows the Lunar Phase Assembly as presently understood isolated from the larger mechanism. Right image ("B") shows the pin only. Light peening or bending of the inserted end of this pin would bave been sufficient to ensure a tight friction fit sufficient to carry the torque required to drive this assembly, that could also be overcome by the operator for the purposes of setting as described above. 
One might reasonably ask if the pointer showing the true position of the sun might also have required adjustment, and it is conceivable that if it did, it was perhaps done via a process as simple as the gentle advancement of a friction-fit pointer, much like the operation above. However, our position is that a single day advancement in solar longitude is unlikely to have been considered necessary, within the context of the Mechanism's non-trivial backlash. ${ }^{35}$ All other pointers not yet discussed, both extant and conjectured, can be considered as not requiring any angular adjustment, due to the much longer period relationships that drive them.

From this newly corrected state, the Mechanism would then have been operated as normal. The lunar month would continue to commence, at or very close to the same lunar phase as it had done prior to the adjustment, which in the case of the Egyptian lunar calendar was apparently the Moon's last morning visibility. ${ }^{36}$ The lunation sequence as indicated by the Calendar ring and the Metonic calendar would both continue to agree with each other, and the Mechanism would again proceed for another 76 years using the (known-to-be slightly flawed) Metonic period relationship, until once again the Callippic correction event was invoked, as indicated by the Callippic dial. This correction cycle would have been perpetual, subject only to the other limitations of the Mechanism.

In this way, assuming 'forward' motion of the Mechanism, the calendar ring dial rotates backwards by one full day every 76 years, and so in principle at least, requires the existence of 354 holes (one for each day of the lunar year). It should be noted that the correction process described above would also apply in reverse if the Mechanism were to be operated in 'reverse', notwithstanding the need to correct for unavoidable backlash, in the event of reversal. ${ }^{35}$

Intercalation of the lunar calendar. Aside from the use just described, the Calendar ring holes also permit convenient intercalation of a '13th month' to be executed as required. Intercalation is the process whereby a single month of a lunar calendar is 'repeated' once every two to three years to reconcile the lunar and solar cycles. In practical terms, because of the Mechanism's movable Calendar ring design, this would only require the Calendar ring be rotated clockwise by one month to permit the month just passed to be repeated. When intercalation is considered in combination with the Callippic cycle correction, it becomes clear that as the Calendar ring is progressively rotated to accommodate the Callippic cycle correction, all 354 holes underlying the calendar ring are eventually called into service, and are, therefore, an essential design feature of the Mechanism.

The intercalation proposal favored by the authors is a simple correction event triggered by direct lunar observation, which would easily provide convenient synchronization with, for example, the start of the Egyptian civil calendar. This would be the simplest approach and resembles the proposal of Depuydt. ${ }^{37}$ Parker also proposed just such a simple intercalation as the predecessor of the more structured intercalation of the Carlsberg 9 calendar, which could be applied as a formal means of achieving reconciliation between the proposed lunar calendar and the Egyptian civil calendar over a 25 -year cycle. ${ }^{36}$

An additional advantage is that operation in accordance with the extant Metonic dial would also have been possible, and if one chose to use a formal intercalation system such as this, it would benefit from a physical representation of the passage of lunations represented in days, on a separate dial upon the Mechanism. This would address the need for keeping track of days required to be excluded to reflect the "hollow" months (those of 29 days) of a regulated calendar, an issue identified in the Metonic context by Freeth et al. who observed that "...a display of the days of the lunar month seems essential". ${ }^{23}$

Presently there is insufficient data to clarify this matter, or the issue of exactly how the nominal 29day and 30-day month periods were distributed around the Calendar ring. However, if the Calendar ring was indeed intended as a representation 12 lunations, then a simple alternating pattern $(29 / 30 / 29 / 30 \ldots)$ would suffice. Referencing a fixed fiducial mark, perhaps the one identified by 
Price, ${ }^{1}$ the user could rotate the dial clockwise by one lunar month when intercalation is required, and so readily alternate between 29- and 30-day intercalation intervals, thus maintaining an average synchronization with the Callippic cycle correction.

The cultural significance of an Egyptian lunar calendar. The presence of Egyptian month names (rather than Corinthian month names, as on the Metonic calendar ${ }^{38}$ ) suggests the lunar calendar was included in the Mechanism's design with the intention that it reflect a different cultural view from the Metonic calendar. Today, the precise nature of such a calendar is still unsettled in the literature, but to properly understand the modern state of the issue, one must first become familiar with one of the more forthright discussions regarding the calendars of Ancient Egypt: The 1950's exchange between Gardiner and Parker regarding The Problem of the Month-Names. ${ }^{39,40}$

Two components framed the problem. First, depending on the source, some festivals do not actually occur in their eponymously-named months, but rather on the first day of the following month. ${ }^{41}$ And second, the final month of the civil calendar is sometimes presented as the first, depending on which ancient source is referenced. ${ }^{42}$

In his original paper on the subject, Gardiner proposed a resolution involving two civil calendars, running concurrently, such that one was always one month behind the other. ${ }^{41}$ Parker disagreed and asserted the existence of three calendars: An "original" 354-day lunar calendar, the well-documented 365-day civil calendar, and a third 354-day "later" lunar calendar based upon the 365-day civil calendar, ${ }^{36}$ about which Parker later wrote was "devised to accompany the civil year in its wandering, naturally borrowed its month-names from those in common use in the civil calendar" (emphasis added). ${ }^{40}$ Since neither scholar's position could accommodate the other's on the matter of lunar calendars, this resulted in near mutually-exclusive interpretations of supporting calendrical data and initiated something of an unresolved schism on this topic. Despite broad acceptance of the 365-day civil calendar, the dearth of primary data ensured the debate surrounding Parker's lunar calendars continued unresolved.

Several decades later, Depuydt further refined Parker's proposal of a "later lunar calendar" into a "civil-based" lunar calendar, reaffirming explicit and dependent links to the 365-day civil calendar, of which the most relevant to this discussion is Depuydt's conjectured use of the 365-day civil calendar month names in a lunar calendar context. ${ }^{37,42}$ However, this proposal was presented amidst much dissent on the matter, with positions ranging from acceptance of both of Parker's proposed lunar calendars, to acceptance of only the original lunar calendar, to outright rejection of any Egyptian lunar calendars at all. .9, $43,44,45,46,47,48,49,50^{2}$

With our finding however, we can propose that a fundamental question - the existence of the Egyptian "civil-based” lunar calendar-has possibly gained some supporting evidence. The Antikythera Mechanism construction dates to between 205 B.C. and the mid-first century B.C., 9,12,15,38 placing it within the era of the proposed civil-based lunar calendar. ${ }^{40,42}$ It has three Hellenized Egyptian month names on the Calendar ring, ${ }^{14}$ and the Mechanism's Calendar ring exhibits 354 divisions, the number expected for a lunar calendar.

Parker and Depuydt have both theorized the existence of the later Egyptian lunar calendar and predicted its month names would be drawn from the civil calendar. ${ }^{37,40}$ Based on the above, we suggest that the Front Dial Calendar Ring of the Antikythera Mechanism is possibly the first example of the Egyptian civil-based lunar calendar proposed by R. A. Parker in $1950 .^{36}$

Hiding in plain sight. Finally, we would like to address the question of how a calendar of 365 days has become so widely presumed in the literature without challenge, and for so long.

Upon inspection of the Mechanism in 1905, Albert Rehm first noted the presence of two consecutive Egyptian month names, ${ }^{22}$ and then Price subsequently proposed the outside ring on the 
Mechanism's front dial to be an example of the 365-day Egyptian calendar. ${ }^{1}$ As research and the literature progressed, quite reasonably, the 365-day conjecture appears to have been taken as fact. The Egyptian civil calendar is after all, prominent in the literature, and was undeniably in continuous use before, during, and after the epoch of the Mechanism. Importantly, the discrepancy that is the focus of this paper is not quite so large or obvious as to be intolerably inconsistent with this presumption, especially given the incomplete and degraded state of the artifact. And so, until the era of advanced imaging, there has been little to formally provoke a rigorous testing of the 365-day presumption as a hypothesis.

We would therefore like to draw attention to the fact that it was the process of constructing a high fidelity physical reproduction of the Mechanism, based upon the more recent imaging, that first alerted the authors to the possibility that an error had perhaps been made in the interpretation of the Calendar ring feature. Were it not for this process of reconciling high quality images with a faithfully constructed model, one could reasonably presume this discrepancy would have continued unnoticed. On this basis we believe it is reasonable to suggest that the study of any ancient mechanism would benefit by an accompanying parallel process of mechanical validation by researchers possessing an understanding of, and practical experience in, the craft that is now understood to have its roots firmly embedded in the line of technology that this Mechanism represents: antiquarian horology. ${ }^{1}$ This would not only provide physical validation and readily dispatch untenable proposals, but it would also assist in properly illuminating the reality embodied in an ancient device.

Future research. Based on the assumption of a 365-day Egyptian Civil Calendar, the Calendar ring has until now been believed to be out of the correct orientation for the assumed epoch of the Mechanism. Therefore, this observation has generally been considered confounding with respect to establishing or verifying the epoch and has been variously dismissed as either careless or accidental positioning of the calendar ring. ${ }^{1,15,17}$ Given that the dial is not a 365-day civil calendar as previously assumed, it should no longer be dismissed as confounding data, and the potential significance of its present orientation in regard to the epoch of the Mechanism should be re-examined within a lunar calendar context. Similarly, much of the scholarly work that has been conducted to determine the origin, destination, and purpose of the Mechanism, may also benefit from the consideration of this new data.

It is also worthwhile noting this discussion is, at present, conjectural. Nevertheless, there is merit in considering the possibilities in a reasoned and careful manner, and presenting opinions tightly bound to a series of hypotheses so that our understanding might be modified as the data is improved in the future. We very much encourage, and look forward to the continuation of this discussion.

Study Limitations. Despite having access to high-resolution projections of the Mechanism, there are limits to the quality of the images. A few holes, for example, are filled with debris, making it more difficult to settle on a hole center, resulting in our measuring some holes many times to reduce measurement noise. Different projections or higher-resolution scans may resolve these holes more clearly.

As a final note, access to data, especially projected CT images of the Mechanism are technically difficult to acquire. The Antikythera Mechanism Research Project was gracious to accommodate us and is working to make the raw data more widely available. But non-trivial expense and effort is required to produce usable purpose-driven projections from the raw data. Funding, as is often the case, is at issue. We would like to see more empirical studies of the Mechanism and hope science organizations worldwide recognize the unexplored potential of the Mechanism. 


\section{References}

1. Derek de Solla Price, 'Gears from the Greeks. The Antikythera Mechanism: A Calendar Computer from ca. 80 BC', Transactions of the American Philosophical Society (1974), pp1-70.

2. Michael T. Wright, 'Counting Months and Years: The Upper Back Dial of the Antikythera Mechanism', BULLETIN-SCIENTIFIC INSTRUMENT SOCIETY vol. 87 (2005), pp8-13.

3. Michael T. Wright, 'The Antikythera Mechanism and the Early History of the Moon-Phase Display', Antiquarian Horology vol. 29, issue 3 (2006), pp319-329.

4. Michael T. Wright, 'The Front Dial of the Antikythera Mechanism', in Explorations in the History of Machines and Mechanisms. (Springer, 2012), pp279-292.

5. M. T. Wright, 'The Antikythera Mechanism: Compound Gear-Trains for Planetary Indications', Almagest vol. IV, issue 2 (2013), pp4-31.

6. Tony Freeth and Alexander Jones, 'The Cosmos in the Antikythera Mechanism', IS AW Papers (2012), pp1-63.

7. Michael T. Wright, 'In the Steps of the Master Mechanic', University of Patras, 12-17.

8. Tony Freeth, Yanis Bitsakis, X. Moussas, J. H. Seiradakis, et al., 'Decoding the Ancient Greek Astronomical Calculator Known as the Antikythera Mechanism', Nature vol. 444 (November 2006), pp587-591.

9. Tony Freeth, 'Eclipse Prediction on the Ancient Greek Astronomical Calculating Machine Known as the Antikythera Mechanism', PLoS ONE vol. 9, issue 7 (July 2014), pp1-15.

10. Christián C. Carman and Marcelo Di Cocco, 'The Moon Phase Anomaly in the Antikythera Mechanism', IS AW Papers (2016), pp1-40.

11. Tony Freeth, 'Revising the Eclipse Prediction Scheme in the Antikythera Mechanism', Palgrave Communications vol. 5, issue 1 (January 2019), pp1-12.

12. J. H. Seiradakis and M. G. Edmunds, 'Our Current Knowledge of the Antikythera Mechanism', Nature Astronomy vol. 2, issue 1 (January 2018), pp35-42.

13. Alexander Jones, 'The Epoch Dates of the Antikythera Mechanism (With an Appendix on Its Authenticity)', IS AW Papers vol. 17 (2020), .

14. Yanis Bitsakis and Alexander Jones, 'The Front Dial and Parapegma Inscriptions', Almagest vol. 7, issue 1 (2016), pp68-137.

15. Christián Carman and James Evans, 'On the Epoch of the Antikythera Mechanism and Its Eclipse Predictor.', Archive for History of Exact Sciences vol. 68, issue 6 (November 2014), pp693774.

16. M. G. Edmunds, 'The Antikythera Mechanism and the Mechanical Universe.', Contemporary Physics vol. 55, issue 4 (August 2014), pp263.

17. James Evans and Christián C. Carman, 'Babylonian Solar Theory on the Antikythera Mechanism', Archive for History of Exact Sciences vol. 73, issue 6 (2019), pp619-659.

18. Jian Lin and Hong Yan, 'Decoding the Moon Phase Display Device over the Front Dial of the Antikythera Mechanism.', Chinese Journal of Mechanical Engineering vol. 28, issue 4 (July 2015), pp676.

19. Maria K. Papathanassiou, 'Reflections on the Antikythera Mechanism Inscriptions', Advances in Space Research vol. 46 (January 2010), pp545-551.

20. Aristeidis Voulgaris, Andreas Vossinakis, and Christophoros Mouratidis, 'The New Findings from Antikythera Mechanism Front Plate Astronomical Dial and Its Reconstruction', Archeomatica (December 2017), pp14. 
21. Michael T. Wright, 'The Antikythera Mechanism Reconsidered', Interdisciplinary Science Reviews vol. 32, issue 1 (March 2007), pp27-43.

22. Alexander Jones, A Portable Cosmos: Revealing the Antikythera Mechanism, Scientific Wonder of the Ancient World, (Oxford University Press, 2017).

23. Tony Freeth, Alexander Jones, John M. Steele, and Yanis Bitsakis, 'Calendars with Olympiad Display and Eclipse Prediction on the Antikythera Mechanism', Nature vol. 454 (July 2008), pp614.

24. James Evans, Christián C. Carman, and Alan S. Thorndike, 'Solar Anomaly and Planetary Displays in the Antikythera Mechanism', Journal for the History of Astronomy vol. 41, issue 1 (February 2010), pp1-39.

25. Andrew T. Ramsey, 'The Latest Techniques Reveal the Earliest Technology-A New Inspection of the Antikythera Mechanism', Proceedings of the International Symposium on Digital industrial Radiology and Computed Tomography, 25-27.

26. Lukas Bulwahn, 'Intersecting Chords Theorem', Archive of Formal Proofs (2016), pp1-7.

27. Johannes Schindelin, Ignacio Arganda-Carreras, Erwin Frise, Verena Kaynig, et al., 'Fiji: An Open-Source Platform for Biological-Image Analysis', Nature Methods vol. 9 (June 2012), pp676.

28. Daniela Ushizima, Andrea G. C. Bianchi, Christina DeBianchi, and E. Wes Bethel, 'Material Science Image Analysis Using Quant-CT in ImageJ', Proceedings of the ImageJ Developers Meeting, 7.

29. Joseph F. Hair, William C. Black, Barry J. Babin, and Rolph E. Anderson, Multivariate Data Analysis, (Cengage Learning EMEA, Upper Saddle River, NJ, 2018).

30. Daniël Lakens, 'Equivalence Tests: A Practical Primer for t Tests, Correlations, and MetaAnalyses', Social Psychological and Personality Science vol. 8, issue 4 (May 2017), pp355-362.

31. D J Schuirmann, 'A Comparison of the Two One-Sided Tests Procedure and the Power Approach for Assessing the Equivalence of Average Bioavailability.', Journal of Pharmacokinetics and Biopharmaceutics vol. 15, issue 6 (December 1987), pp657-680.

32. JMP® Pro, (SAS Institute Inc., Cary, NC, 1989).

33. Jacob Cohen, Statistical Power Analysis for the Behavioral Sciences, (Routledge, 2013).

34. Otto Neugebauer, 'Periods and Mean Motions', in A History of Ancient Mathematical Astronomy. (Springer, New York, NY, 1975), pp388-391.

35. M. G. Edmunds, 'An Initial Assessment of the Accuracy of the Gear Trains in the Antikythera Mechanism', Journal for the History of Astronomy vol. 42, issue 3 (August 2011), pp307-320.

36. Richard Anthony Parker, The Calendars of Ancient Egypt, (University of Chicago Press, 1950).

37. Leo Depuydt, 'From Twice Helix to Double Helix: A Comprehensive Model for Egyptian Calendar History', Journal of Egyptian History vol. 2, issue 1 (2009), pp115-147.

38. Paul A. Iversen, 'The Calendar on the Antikythera Mechanism and the Corinthian Family of Calendars', Hesperia: The Journal of the American School of Classical Studies at Athens vol. 86, issue 1 (2017), pp129-203.

39. Alan Henderson Gardiner, 'The Problem of the Month-Names', Revue d'Égyptologie vol. 10 (1955), pp9-31.

40. Richard Anthony Parker, 'The Problem of the Month-Names: A Reply', Revue d'Égyptologie vol. 11 (1957), pp85-107.

41. Alan Henderson Gardiner, 'Mesore as First Month of the Egyptian Year', Zeitschrift Für Ägptische Sprache Und Altertumskunde vol. 43, issue 1 (December 1906), pp136-144.

42. Leo Depuydt, Civil Calendar and Lunar Calendar in Ancient Egypt, (Peeters Publishers, 1997).

43. Anthony J. Spalinger, 'Ancient Egyptian Calendars: How Many Were There?', Journal of the American Research Center in Egypt vol. 39 (2002), pp241-250. 
44. Jürgen von Beckerath, 'Das Kalendarium Des Papyrus Ebers Und Das Sothisdatum Vom 9. Jahr Amenophis'I.', Studien Zur Altägyptischen Kultur (1987), pp27-33.

45. Christian Leitz, 'Studien Zur Ägyptischen Astronomie', Wiesbaden: O. Harrassowitz, 1989. (1989),

46. Ulrich Luft, 'Remarks of a Philologist on Egyptian Chronology', Ägypten Und Levante/Egypt and the Levant vol. 3 (1992), pp109-114.

47. James P. Allen, The Heqanakht Papyri, (Metropolitan Museum of Art New York, New York, NY, 2002).

48. Juan Antonio Belmonte Avilés, 'Some Open Questions on the Egyptian Calendar: An Astronomer's View', Trabajos de Egiptología = Papers on Ancient Egypt issue 2 (2003), pp7-56.

49. Rolf Krauss, 'Lunar Days, Lunar Months, and the Question of the 'Civil-Based' Lunar Calendar', in Eric Hornung, Rolf Krauss, and David A. Warburton, eds., Ancient Egyptian Chronology. (Brill, 2006), pp386-391.

50. Marshall Clagett, Ancient Egyptian Science: Calendars, Clocks, and Astronomy, (American Philosophical Society, 1989).

\section{Acknowledgements}

C.B. particularly thanks Clickspring patrons, and also thanks Michael Wright, Alexander Jones, Dennis Duke, and Alexander Lipton for reviewing early drafts of this paper. A.T.T. thanks Maggie for her reviews and support. Funding: No outside funding sources were used. Author contributions: Conceptualization: C.B. lead, M.D. supporting. Data curation: A.T.T. lead, A.T.R. supporting. Formal analysis: A.T.T. lead, C.B. supporting. Methodology: A.T.T. lead, C.B. supporting. Supervision: C.B. lead, A.T.T. supporting. Writing—original draft: C.B. and A.T.T. equal. Writingreview and editing: C.B. and A.T.T. equal. Competing interests: Authors declare no competing interests. 